\title{
Pop-Music as a Case-Study of Youth Culture
}

\author{
Alexander Teslenko \\ University “KAZGUU”, Astana, Kazakhstan \\ Email: teslan@rambler.ru
}

How to cite this paper: Teslenko, A. (2016). Pop-Music as a Case-Study of Youth Culture. Advances in Anthropology, 6, 109121.

http://dx.doi.org/10.4236/aa.2016.64010

Received: September 12, 2016

Accepted: November 7, 2016

Published: November 10, 2016

Copyright $\odot 2016$ by author and Scientific Research Publishing Inc. This work is licensed under the Creative Commons Attribution International License (CC BY 4.0).

http://creativecommons.org/licenses/by/4.0/

\section{(c) (7) Open Access}

\begin{abstract}
In article the problem of youth culture through a prism of musical socialization of youth is considered. On the basis of own researches and the secondary analysis of results of sociological polls of other scientists the author analyzes a place and a role of popular music in youth subcultural communities. The youth culture in this case acts as the system of values, installations, ways of behavior and vital styles of a certain group differing from dominating in the society of the culture though its direct genetic generation of a social and psychological dichotomy "We-They". For popular music, first of all, its dancing and entertaining directions are a space of personal improvisation and adaptation to accelerate a post-industrial civilization.
\end{abstract}

\section{Keywords}

Youth, Youth Culture, Youth Contra-/Subculture, Rave Culture, Hip-Hop Culture, Rockers, Popular Music, Rock Music, A Dance Music, Youth Leisure

\section{Introduction}

The youth is the future of society, its perspective state. This understanding of youth brings us to the level of the relational concept of time according to which time is understood as change of qualitative conditions of the changing object. Thus connecting time with youth, first, we note that future society can be seen in that new generation which already actually exists in the present in the form of children's and youth community. Secondly, youths acquire norms and traditions of the "adult" world in concrete sociocultural space actually exist.

The space and time are the fundamental bases of objective processes of socialization. On this background the youth culture acts as independent social space in which young people can find authenticity whereas in a family or school they are deprived of real powers, and are completely controllable by adults (Levikova, 2004). 
In social sciences of the Soviet period the youth was not considered as independent social and demographic group for a long time. Allocation of such group did not keep within the existing ideas of class structure of society, and contradicted the official ideological doctrine about its socio-political unity. The analysis of youth subcultural phenomena until the end of the 1980th years was kept in very narrow framework and was not a little significant area of youth researches (subject of this sort generally had the closed character and its development could not be conducted at a free choice of this or that researcher). The big role in it was played, and also with that in the period of the second half of the XX century, the majority of types of youth subculture had an appearance of peculiar cultural "intervention" from abroad. But basically it was due to the natural to the West subcultures, which were less presented in social and cultural Soviet young people activities.

The situation changed during reorganization and after collapse of the USSR. Youth informal groups began to be formed as aspiration to change of their installations as well as society (for example: "further we'll act"/"Kino" group). Changes in youth consciousness and behavior reflected this thirst for public updating on the basis of philosophical judgment of social values and a specific lifestyle. Leisure and the modern popular music accompanying it take a special place in youth lifestyle, due to wide representation of pop music in mass media, its various genres and the directions, including subcultural, gained fame in society (so-called "CNN effect"). The purpose of this article is to consider a place and a role of popular music in formation of subcultural youth communities and to analyze its influence on system of leisure modern youth.

\section{Methods}

Empirical base of this article consist of sociological studies in the flame of national report "Youth of Kazakhstan-2014" carried out in 2014 by the Center of Youth Researches (Adarno, 1999). In this survey participated at least 2000 respondents aged 14 to 29 from all social group, which reside in 14 regions (oblasts) of Kazakhstan, Astana and Almaty cities. The survey involved 1002 males and 998 girls aged from 17 to 21 years $-60.5 \%, 21$ to 25 years- $16 \%$, from 25 to 36 years $-23.4 \%$ of respondents. Respondents were presented with the following groups: older pupils of $4.6 \%$; students of specialized secondary school-13\%; students and undergraduates- $61.5 \%$ of and of $20.7 \%$ of young professionals. And also other materials of author's researches on a problem of youth leisure and secondary analysis of results of youth researches Kazakhstan and Russian scientists are used in this paper.

\section{Result}

The youth culture is a peculiar form of adaptation to norms, values, a way of life of society, also in the person of youth subculture, the sociocultural homogeneous environment and in a measure of a counterculture acts as a source of transformation of culture certain societies. Some researchers consider practice of subcultures as expression of opposition to the dominating culture (M. Brake, D. Muggleton). Subcultures as "sys- 
tems of values, ways of expression or vital styles" developed the social groups which were in the subordinated situation, "in response to the dominating systems of values: subcultures reflect attempts of such groups to solve the structural contradictions which arose in more societal context" (Brake, 1995: p. 204).

In our working hypothesis the youth culture is, first of all, the system of values, installations, ways of behavior and vital styles of a certain group differing from dominating in the society of the culture though which is its direct genetic generation of a social and psychological dichotomy "We-They".

Not incidentally during sociological poll of $25.5 \%$ of respondents consider that the youth subculture is a lifestyle of modern youth, a special form of self-affirmation and self-identification-23.8\% (Scientific-Research Centre "Youth", 2014). In too time of 20.6\% consider it as temporary age hobby or only a leisure form of self-realization of youth$11.7 \%$, thereby as if dead lined that the youth community is not uniform, general and monolithic part of society today. Moreover, having given in existing in our society to "moral panic", let small, but never the less a certain part of youth considers youth subculture as a form of a social behavior (3.5\%), an outsider's lifestyle or a protest to public norms $(2.4 \%)$, and $12.3 \%$ of respondents in general found it difficult to answer a question: "In your opinion, youth subcultures are ..." (Figure 1).

Really, the youth subculture is a product of informal (free) communication, and the basic regulating principle of relationship-group or age (generational) solidarity and identification in the relations "ME-WE-THEY". Subcultures-result of conscious search of new identity, forming of new style in the most different spheres of sociocultural life (Pilkington, Omelchenko, et al., 2002: p. 67). Stay of young people within this or that subculture and real interest in it to subculture lasts, as a rule, some years that causes instability of its device (see Table 1).

Data of our research show backwardness of the informal youth movement in Ka-

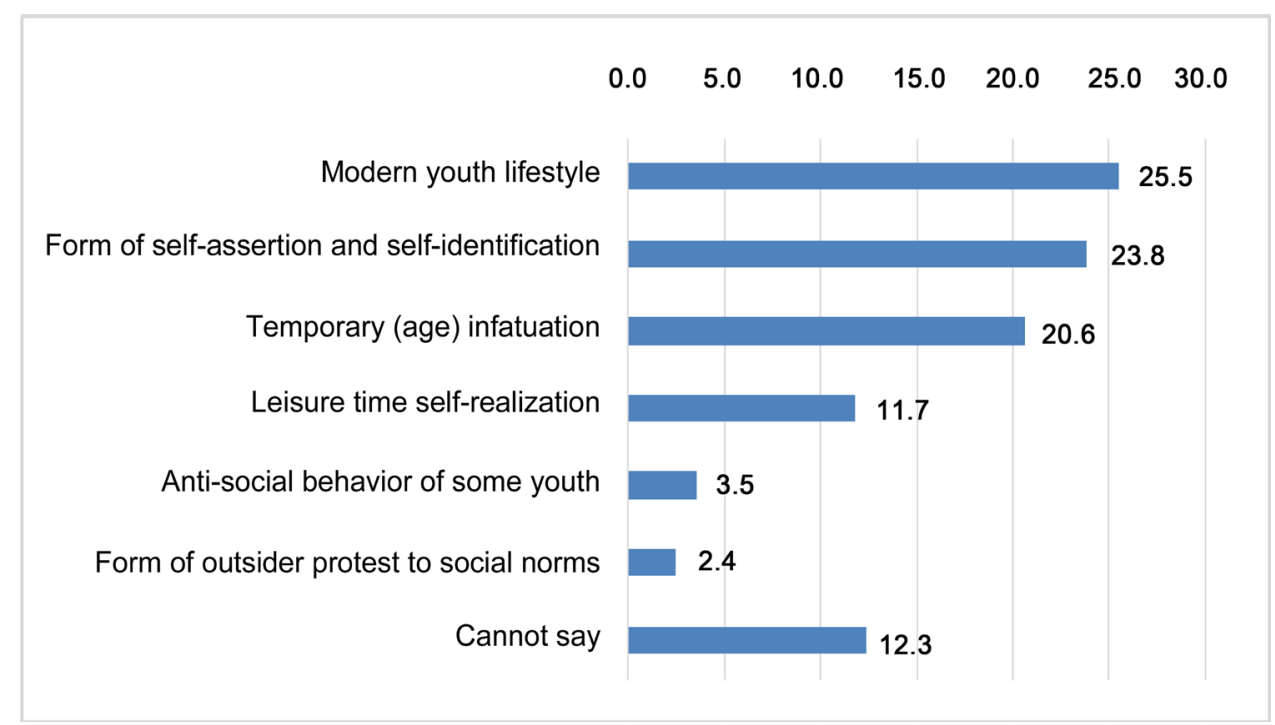

Figure 1. Distribution of answers of respondents to a question: "In your opinion, youth subcultures are ...”, \%. 
Table 1. Distribution of answers of respondents to a question: "Where you feel most comfortable?", \%.

\begin{tabular}{cc}
\hline Versions of answers & Share of respondents \\
\hline At home & 55.6 \\
At work place & 16.4 \\
Among adherents (community) & 15.1 \\
In university/college & 4.0 \\
In the hostel & 0.4 \\
Cannot say & 8.5 \\
\hline
\end{tabular}

Table 2. Distribution of answers of respondents to a question: "Who brought you into community?", \%.

\begin{tabular}{cc}
\hline Versions of answers & Share of respondents \\
\hline Parents & 30.2 \\
Friend & 24.9 \\
Learned about them via social networks & 20.0 \\
Heard from other people & 10.7 \\
On my own & 2.2 \\
Cannot say & 11.6 \\
Purchased attribute (motorcycle) & 0.4 \\
\hline
\end{tabular}

zakhstan: only $11.3 \%$ of participants of poll declared the participation in youth informal communities, and $88.7 \%$ do not identify themselves with the informal movement of youth. Thus only considers $15.1 \%$ of respondents youth subcultural practicians as the most comfortable space, compare to a house situation (55.6\%).

On this background data of answers to a question look surprising: "Who brought you into community?", breaking stereotypes about an imaginary dichotomy "childrenparents". Has parental impact to the dominating-30.2\% of respondents declared that into community of contemporaries they were brought by parents, $24.9 \%$-that them were given by the friend, and only $2.2 \%$ consciously came there (Table 2 ).

The Russian sociologists claim that decisive factors of activization of processes of a group forming and the dominating incentives of association, entries into group are:

- fear to remain in isolation;

- need for safety, understanding, authority, necessity ("there I for the first time felt equal, there I am necessary");

- real possibility of a choice of the most convenient way of the self-affirmation quite often alternative traditional, to the standard standards of behavior, etc. (Lyasnikov \& Lyasnikova, 2003: p. 42).

Answering a question "Than for you participation in informal community is?" respondents declared that it gives them feeling of a freedom of expression (28.0\%), helps to leave from reality $(20.4 \%)$ and to find adherents (19.6\%), to be exempted from daily 
boredom (16.0\%) and the bothered standard norms (14.7\%). The outsider's syndromethat general is available that pulls together youth subcultural community and attracts her members to each other. It is that social and psychological reality which feeds formation of informal groups with asocial and antisocial orientation, and restriction of possibility of satisfaction of requirements and realization of interests accelerate transformation of subjective readiness for a choice of illegal ways of a protest and self-realization into objective reality.

The analysis of empirical data shows that in system of youth communities of Kazakhstan sports subcultures-42.7\% (Table 3) are in the lead. Some of them, for example bikers (from English bicycle-abbr. bike) even have the organizational structures bike-club (in more detail on the Biker.kz portal). In Kazakhstan motorcycles races or on cars at night, parkour and a bodybilding - the special, applying for an elitism world of a man's brotherhood-are in process of formation and there are bases to assume that with growth of welfare of the population in the future they will attract to themselves still bigger number of supporters.

With confidence it is possible to claim that youth music is a dance vigorous music which totals more than 100 different directions and the subdirections. Young people live in "mad" rate of life, seek to reach much therefore they need modern rhythmical music which will daily load them with the energy.

Our research of this year (Table 4) shows that in a leading position in system of musical socialization of youth the dance music of different genres and directions (the disco, funk, euro-pop, etc.).

In many respects confirm the results of the international sociological research "Students as an Image of the Future" yielded our survey which was conducted by Gorshenin's Institute from October, 2010 to March, 2011, the youth of Ukraine, Russia, Kazakhstan and Poland (2012) prefers to listen the pop and rock music In total according to casual selection 5 thousand 155 students in 22 higher educational institutions of four countries were interrogated: Ukraine, Russia, Poland, Kazakhstan. More than a half of

Table 3. Young people note, who/what brought them to informal society, $\%$.

\begin{tabular}{cc}
\hline Sports (bicyclists, bikers, race car driver, etc.) & 42.7 \\
Musical (hip-hop, rap, metal, rock, etc.) & 27.1 \\
Dancing (brake-dance, capoeira, etc.) & 17.8 \\
Glamour & 9.3 \\
Religious & 8.9 \\
Virtual (gamers and other) & 8.0 \\
Artistic & 8.0 \\
Animal lovers & 5.3 \\
Criminal ("gopniks" and other) & 4.0 \\
Enconventional sexual orientation (gay, lesbian, etc.) & 1.8
\end{tabular}


Table 4. Distribution of answers of respondents to a question: "With what styles and genres of popular music you most of all sympathize? (no more than 3 answers)”, \%.

\begin{tabular}{cc}
\hline Versions of answers & Share of respondents \\
\hline Dancing pop music & $36.1 \%$ \\
Rap & $34.3 \%$ \\
Rock-music & $12.8 \%$ \\
Club music (house, techno, etc.) & $8.6 \%$ \\
Russian chanson & $7.9 \%$ \\
Hard'n'heavy (Metal Rock) & $2.8 \%$ \\
Lounge & $2.3 \%$ \\
Ethno-jazz & 1.4 \\
Nothing & $4.4 \%$ \\
Cannot say & $23.9 \%$ \\
\hline
\end{tabular}

the interrogated students in all four countries prefer pop-music (Kazakhstan-57.5\%, Poland-56.9\%, Ukraine-51.6\%, Russia-50.1\%). The second place in the majority of the countries is taken by fate (Poland-53.6\%, Ukraine-49.3\%, Russia-45.0\%). Thus the Kazakh students on the second position had a symphonic music (42.1\%) which took the third place in Ukraine (27.0\%). In Russia and Kazakhstan on the third place became rap ( $43.5 \%$, and $41.4 \%$ respectively), and in Poland-a club style "house" (32.7\%). The considerable part of youth of four countries listens to the jazz, a chanson, R\&B. Such styles as ethno, lounge and funk are less popular among students in Table 4.

For small part of youth-9.3\%, pop music is the important tool not only social and age, but also social-class differentiation. It is about the lifestyle showing direct participation or proximity of the individual to daily practice of demonstrative luxury, an active social life, cult of "eternal spring", hedonism-a glamour. In full so-called "golden youth" or "mazhor" tries to realize it. In separate components ideology and outlook of a glamour got into many spheres of youth consciousness: all has to be beautiful, and is even better smart.

Musical addictions of this part of youth are projected within so-called rave culture. The rave is treated in "The dictionary of modern slang" of $\mathrm{T}$. Thorn as "a wild party (a wild party), dances or a situation of desperate behavior" (Thorne, 1996: p. 421).

Examples of vital style of the most popular, acting in a charismatic role pop idolscarriers (founders) of the corresponding sociocultural examples of behavior, first of all, a night lifestyle. In shape and stylistics of behavior of ravers the idea of withdrawal of the person by nature is realized. Industrial rhythms, characteristic for musical style of ravers, is some kind of alternative to rock music.

"This music incredibly hypnotizes, it is not similar on anything another, it is worth feeling once-and inside something clicks, and you already know in what a highlight in this music, than it is good. And everything, it does not release you never any more. It is not important when the person was born and how old is he, and there are people who 
love fun, dances and a dance music. I love dances, because this place where it is possible to dress up where it is possible to wriggle, laugh loudly where you feel in a neadekvatka, in a nerealka ..." (Armand, 20 years).

According to DJs of the rave clubs operating in the large cities of Kazakhstan the rave culture develops approximately with 5 years' delay in relation to world practice. In too time, in Astana and Almaty an entrance fee in club of 20 - 60 dollars, drinks are on sale at inflated prices, therefore, in local option it in any way not subculture of youth of working quarters what it was in Great Britain during origin.

The musical and entertaining subculture of the middle class arising in Kazakhstan is presented by hip-hop culture. Hip-hoppers took roots in the youth environment of Kazakhstan from the middle of the 1990th years, as one of subcultural forms of development by youth of social subjectivity through creation, development, distribution, development of four main directions: break dance, rap, graffiti and DJing. As a part of elements hip-hop of culture also street-ball (street soccer), a rolling (a certain equipment of a skating), etc. are considered.

Unlike rather passive form of manifestation in social behavior in rave cultures, hip-hop the culture is an active form of self-realization in music and dance. Ideas of DJing and the hip-hop of sounding created by pioneers of hip-hop-DJ Kool Herc, Africa Bambaataa, Grandmaster Flash, DJ Hollywood and Grandwizard Theodore, laid down in Kazakhstan on a fertile field, having generated a large number of imitators and original rap performers.

If originally the hip-hop culture was considered as the direct certificate of a westernization (Americanization) of youth public consciousness, eventually became adaptability of hip-hop concerning various sociocultural systems, in particular mentality of young Kazakhstan citizens is clear. Often youth hip-hop collectives invite to various large presentations, holidays, forums, festivals.

In a number of places the hip-hop groups are given support by public authorities, public associations. With assistance of actions in area hip-hop culture is considered that by origin hip-hop is connected with disinterested interest of city youth in self-expression and development of world around in peculiar subcultural forms. As features hip-hop culture are connected with actions in open territories, in parks, on sports grounds, it became some kind of alternative to youth gangs of criminal character. "Battles" between DJs, competitions between masters of a break dance and rap, according to our research, led to notable positive consequences:

- the general aggression of dismantlings between street gangs decreased, negative energy of opposition was realized in pro-social forms;

- the youth which is carried away by hip-hop distracts from drugs and alcohol as occupation by a break demands sports preparation.

Thus, the hip-hop culture is capable to revitalize considerably a situation in criminal, unsuccessful quarters of the large cities of Kazakhstan. In the noncommercial forms the hip-hop culture does not demand from young Kazakhstan citizens of big financial investments, gives the chance to organize active leisure of a certain part of the youth fo- 
cused on values of this subcultural design.

Especially it is necessary to tell about rather narrow, but rather active and intellectually developed part of youth from families of middle class preferring rock music, first of all, progressive rock.

According to Theodor Adorno, any, even very little musical person, willingly consumes music, but that music which confirms, strengthens in it feeling own "Me" (Adarno, 1999). In this case the rock culture is positioned as youth subculture for which are characteristic emphasis of otherness, originality, self-sufficiency, independence, brutality, aspiration to self-realization and self-updating. These valuable characteristics are peculiar to "generation Y"-generation in which the hippizm quietly adjoins to bourgeoisness elements (quality education, the market competition, creative professions). The youth culture of "generation of independence" is the cornerstone of this style: freedom from ideology and rigid political installations; breadth of views-the high level of tolerance to different manifestations of culture, understanding and search of this difference; the andegraundnost which is shown in love to club communities, east culture the easy raid of snobbery is inherent in them; refusal of obvious social activity, priority of liberal values.

In this youth space intellectualism gets special sense and reputation. Having turned into a fashionable trend, intellectualism is shown through external practicians (subjects of talk, places, forms and quality of leisure, appearance, a specific slang, etc.). The youth of this style seeks "to listen to clever music", "to read clever books", "to watch clever (correct) film", "to hang out in the correct company", that is "it is correct to position themself'. Especially distinctly it is shown in popularity as classical rock groups (Pink Floyd, Led Zeppelin, Genesis, etc.), groups of "a new wave" and modern collectives.

In the majority modern rockers refused the image of 1980-90, including leather jackets and trousers, metal chains and rivets, and also black undershirts with symbolic of rock groups. Perhaps, an exception are representatives a bike movement among which the hard'n'heavy is most popular (after all many metal bands sang of motorcycles and a fast driving as a symbol of freedom, force and independence). Heavy metal is also rather popular among teenagers, natives from unsuccessful and few provided families (59\%).

In general, it is possible to note that musical addictions and subcultural practices of the Kazakhstani youth are rather various and non-uniform that demands the deep analysis.

\section{Discussion}

Youth culture in modern society. The concept of youth culture traces the roots back in the 1920th years when the world of youth of middle class-the world of girls and young men (teenagers) in the atmosphere of the jazz and dances-started being positioned and be approved as a usual image of youth which gradually became a stereotype and mass media of a cliché. The term "youth culture" is included into scientific discourse together with the concept "youth". The birth of concepts contacted T. Parsons 
justification of stability, an orientation and expediency of development of public systems (Parsons, 1998). It was some kind of reflection on post-war revival of the western societies, expression of belief in possibility of stability, wellbeing and prosperity of all his members.

From the point of view of Karl Mannheim, the youth and its activity directly depend on sociocultural characteristics of society in which at present it lives and which defines her behavior and characteristics. "In language of sociology to be young means to stand on the edge of society, to be in many respects the outsider. And it is valid, a distinctive feature young is lack of the interest in the existing order fixed by the law-they did not make the contribution to economic and psychological structure yet. <...> This position of the outsider-much more important factor defining openness and tendency to changes, than biological maturing. Besides, it coincides with a position of other groups and individuals, for other reasons who appeared on the edge of society such as oppressed classes, people of liberal professions-poets, actors, etc.” (Mannheim, 1994: p. 92).

The marginal status of youth, however, is a temporary phenomenon and subsequently is, as a rule, overcome in favor of more or less stable social status. The same happens and to the cultural values having distribution in the environment of youth culture. The periphery is brightly painted, marked-a kernel "normally", that is has neither color, nor a smell, it "simply exists". Therefore the victory of this or that semiotics system is its moving to the center and inevitable "decolouration". It is possible to compare a "usual" age cycle with it: the revolting young people over the years become "normal" respectable gentlemen, making simultaneous evolution from defiant "okrashennost" to “decolouration" (Barker, 1999: p. 66).

In this regard Karl Mannheim notes: "Penetration into society from the outside forces youth to sympathize with the dynamic social movements which show discontent with the existing state of affairs for absolutely other reasons. The youth still has no interests fixed by the law, neither the economic, nor valuable, available for the majority adults. By it is explained that fact that in youth many act as jealous revolutionaries and reformers, and later, having got permanent job and having got a family, turn into defense and support preservation of status quo" (Mannheim, 1994: p. 173).

Understanding of the marginality, "peculiarity", otherness in relation to other society makes related youth as the "situational", connected with a transitional phase of life intellectuals type with others: professional and local. In addition, similar understanding promotes consolidation of youth as the sociocultural phenomenon repeating in time and space and having impact on other social groups and on the sociocultural world in general, and music world in particular.

The dominating culture and youth constantly interact with each other therefore dynamic changes in both cultures are noted (Sorokin, 1992). Youth culture, being culture in culture, naturally, it is inconceivable and does not exist in itself-out of the dominating culture of modern society. These two cultures- "maternal" and "affiliated" are closely interconnected and complemented. And both in maternal, and in affiliated cul- 
tures, along with preservation of tradition, there is a constant operating time new, with only that difference that if the norms and symbols created and accepted within the dominating culture set the basic principles of streamlining of all society, the norms and symbols created and accepted within youth culture set the basic principle of streamlining of concrete community (subculture).

Youth subcultures are not simply social constructs ideological (according to Cohen), and sociocultural constructs by means of which young people seek to win for themselves cultural space, real time for rest and leisure, a place necessary to them on streets and in gates. "We" help young to allocate and appropriate subcultures subjective excellent from traditionally adult ("THEY") at the level of actually cultural stereotypes of the younger generation: "our" music, "our" fashion, "our communication", etc. They are focused round key opportunities of social interaction: the days off, the disco, travel on vacation, a night exit in the center, etc.

The further destiny of the norms and symbols accepted in youth culture will depend on a number of factors, among which timeliness and inopportuneness, compliance or discrepancy to requirements, readiness or unavailability of young people to their perception and others. Taking into account these and some other factors there are three scenarios according to which events develop:

- they can be unclaimed even within youth culture;

- they can be demanded only within concrete subcultural educations;

- they can pass into the category of the dominating.

As we deal with mutual process, it is possible to say that the listed all three options belong to both cultures-and dominating, and youth culture. And it means that in the culturological plan it is possible to speak about "music for youth" and "youth music". The first is associated with show business, professional composers and performers within show business and show business, and the second-with a musical underground and independent musicians and performers.

These both musical forms are basic, but the attention of researchers to them is rather unequal. The attention of the Russian and Kazakhstan researchers more often attracts a rock underground. As a rule, this results from the fact that it is considered to be that the Russian-speaking fate differs from western (English-speaking) in importance of texts in comparison with music. Really, the majority of groups of the Russian rock began the career in an underground and for them the main thing are texts. From other point of view, it is possible that the big importance of texts (in relation to music) is explained also by rather poor development of musical performing equipment and inaccessibility of high-quality record.

Nevertheless, as show researches, the most part of "usual" youth do not listen to rock music because of its texts: for it, just first of all, needs a dancing rhythm, sound and laser effects, and whose music, in what language songs in what sense of words-all this is not important at all are sung. However that texts are not of great importance, does not mean at all that places of her concentration (a discothèque, a rave party, etc.) less interesting and less culturally spaces, significant for youth. 
The dance music always played a role of an irritant and the destroyer of norms in relation to a pop mainstream-still itself did not turn into a component of a musical landscape. So was once with rock music, so "tamed" "techno" and "house", so entered into a framework of decencies (though yet not up to the end) hip-hop. Opposition always went not only in the area of "WE (young)-THEY (adults)", but also by the intellectual principle: "music for feet" traditionally was considered as entertainment stupid. There were, in other, attempts to varnish reality and at least formally to designate a certain brainwork in compositions for a dance floor, but so-called "intelligent dance music" silently came to naught at the beginning of 2000th years, it is simple because under it was boring to dance.

But dances is serious business even if during them young people do not think of anything. Value of a dance music is shown not only in its hearing, in the rituals connected with corporal pleasure music, but also in a special form of musical socialization of youth, stimulating her individual imaginations.

Leisure in its dancing and musical form is an alternative of reality as well as the way of its expression can include magic "simply for itself". Young people really look for the manned world-pubs, clubs, disco halls, where they will not be under control. But also adults have done, who dare to have a rest, dream, show the hidden, "underground" values behave.

The great share of time, forces of the young man is devoted today to an educational or production activity which is autonomous on the relation with the local environment, the territory. Information, norms, rules, everything that we call in life "fashion" do not go from the local environment. Mass media, show business level leisure of youth of different regions, giving it uniform measurement. Prestigious models of leisure are introduced on provincial communities from the outside, go from the large cultural centers. Besides, they generate the type of society alternative to the basic. As alternative of "official" institutes of socialization, peculiar "counter-groups" of leisure are formed. And if identification of the personality within formal groups (student's group, a work collective, a family) weakens, identification with groups of leisure, on the contrary, amplifies (Teslenko, 2007: p. 86).

In the late $70^{\text {th }}$-the beginning of the 70th years, having faced acute social and pedagogical issues, the western society addressed to phenomenology, strengthened influence of humanistic psychology-instead of a utopia of the bright future leaving out of limits of today, it offered the leisure utopia creating counter system of hedonism and operating already "here and now" - at the end of the working day, working week, an annual cycle. Instead of the principle of social utilization of leisure (leisure as restoration of forces for work, means of "all-round development of the personality", etc.) the principle of individualistic assignment of leisure by the personality considering it was put forward is exclusive as a way socially not of controlled self-realization (from positions of A. Maslow, E. Fromm's “self-realization"). Freedom of creativity which left official institutes of socialization was compensated by leisure as time of sociocultural creativityrelaxed personal improvisations. 
The western civilization ran risks of asocial leisure, realizing that the individuals seduced by leisure do not want to come back to a bosom of social institutes, to burden of daily duties. The risk of a social detraining, demobilization of generations undoubtedly existed and exists, but it the same order, as risk of business or scientific creativity.

Perhaps, the non-conformism of youth leisure is one of ways of interruption of inertia of development of the personality which meet mistrust today, and tomorrow, is not excluded, will become essential? I think, this precedent will not keep itself waiting long. First, on the one hand, the considerable part of young Kazakhstan citizens owing to age predisposition to seek for self-realization and self-affirmation, with another-in the Kazakhstan society the need for charismatic persons which to prove out and without dangerous consequences is great can only in youth culture. Secondly, the processes of globalization and a westernization of a way of life of youth broadcast through mass media and the Internet will also dominate further in youth consciousness and behavior. And, at last, in the third, opposition of east mentality western which is considered today as the problem, can give rise tomorrow to that form of tolerant culture to which to aspire the whole world. And if for other countries, this tendency wears more likely a uniform of expectation and desirable changes, such form of sociocultural integration is integrally necessary for multicultural Kazakhstan. Being on a joint of the West and East as in geographical, and culturally and political sense, Kazakhstan feels need of the practical solution of this problem since the difference of attitude is felt here more tensely as various cultures in the most basis adjoin in each concrete Kazakhstan city or a mudflow.

\section{Conclusion}

The youth culture as sociocultural system is characterized by the following features:

1) It is part, or even a subsystem of that society to which the youth belongs (from here and a prefix sub-pointing to subordination, in the word "subculture"). However it always keeps a relative autonomy and independence. But there is no certain uniform, complete, isolated youth culture. And there is an eclectic mixture, a time of mutually exclusive positions. The excellent point of view has the hidden strategic discrimination character that reduces value of youth culture to value of the local sociocultural phenomenon limited to limits only of youth as "world outlook unripe part of the population".

2) The youth culture represents the homeostasis differing in democracy and mobility. It includes a number of more or less pronounced signs (valuable orientations, standards of behavior, a slang, ways of pastime, etc.), each of which possesses rather steady structure which is adequately answering to the changing sociocultural realities. Expressiveness of these or those signs and a measure of its registration in general depends on age and a measure of extremeness of living conditions of its carriers.

3) Youth cultures of the different countries at the seeming typicalness, obtain their features. For example, in the West and in the former USSR rock music as a symbol of youth culture, however accents deeply national: if in the West the RHYTHM was a core of a genre, in "Russian rock" the WORD was that. 
4) The youth culture is a product of informal (free) communication, and the basic regulating principle of relationship - group or age (generational) solidarity. Social interaction in them is, as a rule, depersonalized. At the same time, these informal "parties" for youth serve as means of self-determination that reference group, ranking themselves to which, the young man finds the place in the relations "I-we-THEY".

5) The most brightly social and psychological contra "We-They", is especially clearly shown at the level of actually cultural (in narrow sense) stereotypes of the younger generation: there is "our" music, "our" fashion, "our" communication.

6) The analysis of information on the ravers, rappers and other youth communities founded on the borrowed lifestyles shows that such communities with their corporate rules and examples of behavior, clothes, musical tastes are only the socialization elevator in modern information society. They in this sense are some completion of social reality for mitigation of intensity at entry into public structures.

7) Popular music is an actual form of musical culture, characteristic for a thought way and an image of action of modern youth. It has essential impact on a valuable kernel of the existing cultural system that allows to consider youth culture at the same time as the adaptation and innovative environment.

\section{References}

Adarno, T. (1999). Selected Works. Sociology of Music. Moscow: University Book.

Barker, A. M. (1999). Consuming Russia: Popular Culture, Sex and Society since Gorbachev. Durham, London: Duke University Press.

Brake, M. (1995). The Sociology of Youth Culture \& Youth Subculture in America, Britain and London. London: Routledge \& Kegan Paul.

Mannheim, K. (1994). Diagnosis of Our Time. Moscow: Urist.

Scientific-Research Centre "Youth" (2014). Youth of Kazakhstan-2014. National Report, Astana: SRC "Youth".

Levikova, S. I. (2004). Youth Subculture. Moscow: Fair-Press.

Lyasnikov, N. V., \& Lyasnikova, Yu. V. (2003). Social and Economic Conditions of Formation of Spiritual Culture of Student's Youth (Sociological Aspect). Moscow: VNIIFK Publishing House.

Parsons, T. (1998). System of Modern Societies. Moscow: Aspect Press.

Pilkington, H., Omelchenko, E., et al. (2002). Looking on the West? Cultural Globalization and Russian Youth Cultures. University Park: The Pennsylvania State University Press.

Sorokin, P. (1992). Human. Civilization. Society. Moscow: Politizdat.

Teslenko, A. N. (2007). Cultural Socialization of Youth: Kazakhstan Model. VTB United League: Saratov-Astana.

Thorne, T. (1996). Dictionary of Modern Slang (p. 421). Moscow: Veche, Perseus.

Youth of Ukraine, Russia, Kazakhstan and Poland Prefer Pop-Music (2012).

http://korrespondent.net/showbiz/music/1213966-opros-molodezh-ukrainy-rossii-kazahstanai-polshi-predpochitaet-pop-muzyku 